Supporting Information

\title{
Ionic Self-Assembly of Giant Vesicle as Smart Microcarrier and Microreactor
}

Jinglin Shen ${ }^{\mathrm{a}}$, Xia Xin ${ }^{\mathrm{a}, \mathrm{b}}{ }^{*}$, Teng Liu ${ }^{\mathrm{c}}$, Shubin Wang ${ }^{\mathrm{a}}$, Yingjie Yang ${ }^{\mathrm{a}}$, Xiaoyu Luan ${ }^{\mathrm{a}}$, Guiying Xu ${ }^{\mathrm{a}}$ ${ }^{\mathrm{b}}$, Shiling Yuan ${ }^{\mathrm{a} *}$

${ }^{a}$ Key Laboratory of Colloid and Interface Chemistry (Shandong University), Ministry of Education, Shanda nanlu No. 27, Jinan, 250100, P. R. China

${ }^{b}$ National Engineering Technology Research Center for Colloidal Materials, Shandong University, Shanda nanlu No. 27, Jinan, 250100, P. R. China

${ }^{c}$ Institute of Materia Medica, Shandong Academy of Medical Sciences, Jinan 250062, P. R. China

\footnotetext{
*Author to whom correspondence should be addressed, E-mail: xinx@sdu.edu.cn.

Phone: +86-531-88363597. Fax: +86-531-88361008

*Author to whom correspondence should be addressed, E-mail: shilingyuan@sdu.edu.cn.

Phone: +86-531-88365896. Fax: $+86-531-88564750$
} 


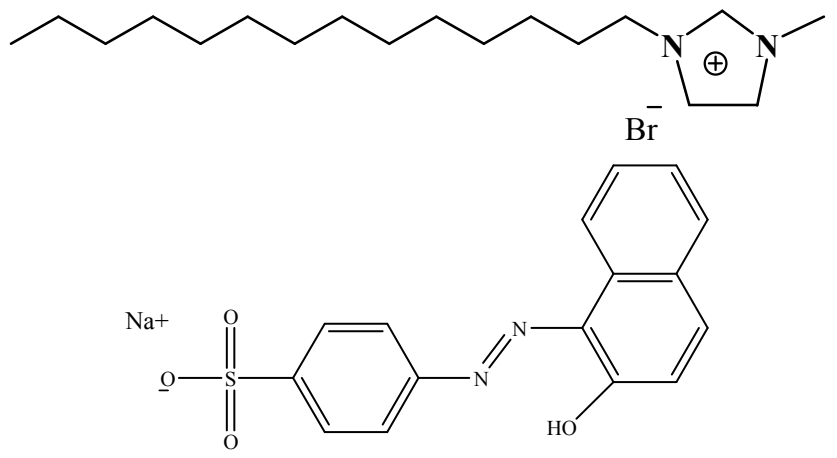

Figure S1. Structures of $\mathrm{C}_{14} \mathrm{mimBr}$ and $\mathrm{AO}$.

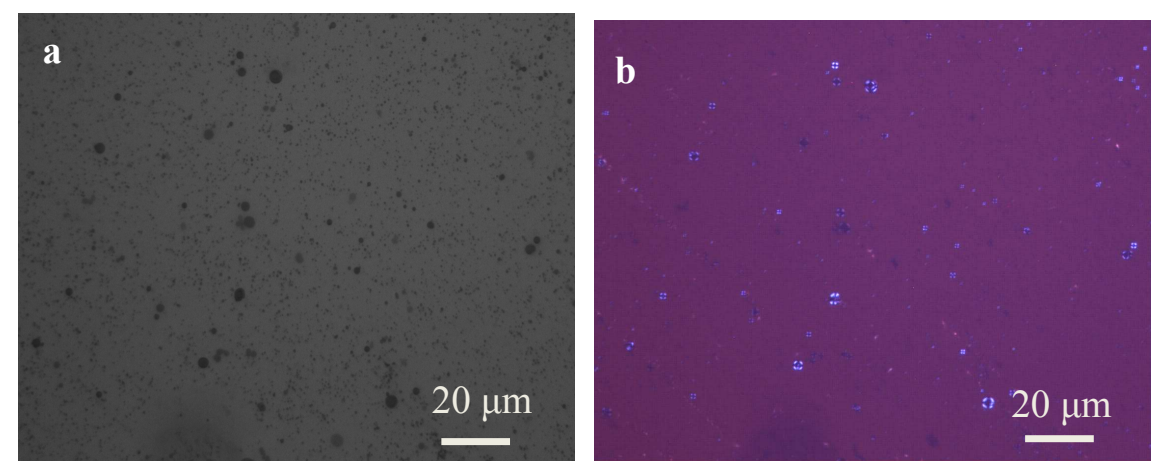

Figure S2. POM images of giant vesicle formed by $0.5 \mathrm{mmol} \mathrm{L}^{-1} \mathrm{AO} / 0.5 \mathrm{mmol} \mathrm{L}^{-1} \mathrm{C}_{14} \mathrm{mimBr}$. (a) without polarized light, (b) with polarized light. 
(a)

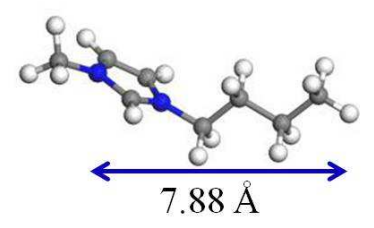

(b)

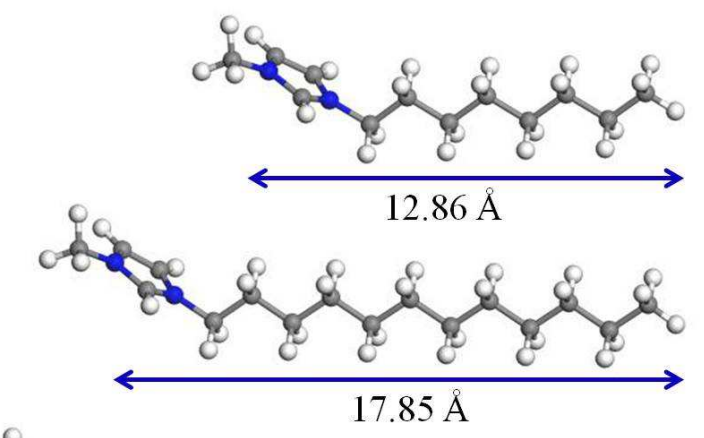

(c)

(d)

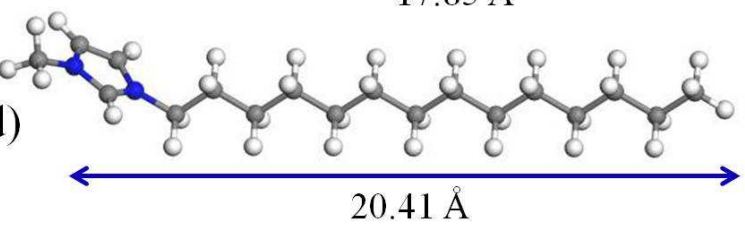

Figure S3. Geometries of (a) $\left[\mathrm{C}_{4} \mathrm{mim}\right]^{-}$, (b) $\left[\mathrm{C}_{8} \mathrm{mim}\right]^{-}$, (c) $\left[\mathrm{C}_{12} \mathrm{mim}\right]^{-}$, (d) $\left[\mathrm{C}_{14} \mathrm{mim}\right]^{-}$with the $\mathrm{PCM}$ procedure optimized at the M06-2X/6-31G(d, p) level.

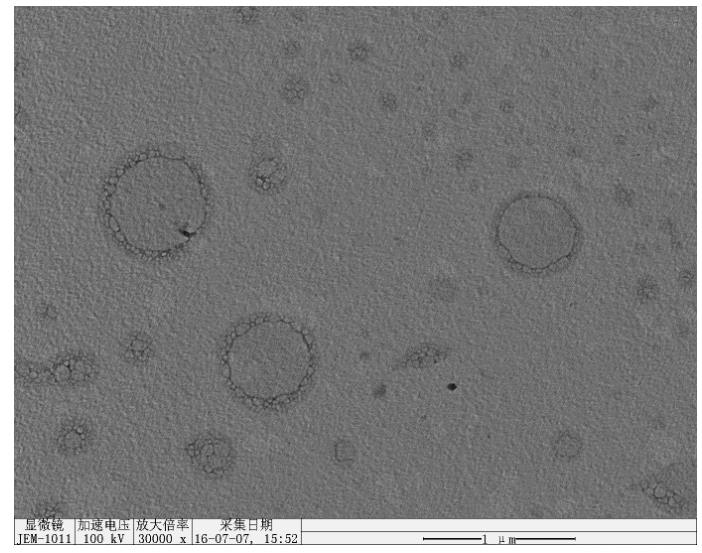

Figure S4. TEM image of $\mathrm{AO} / \mathrm{C}_{14} \mathrm{mimBr}$ self assembly system (four hours later). 


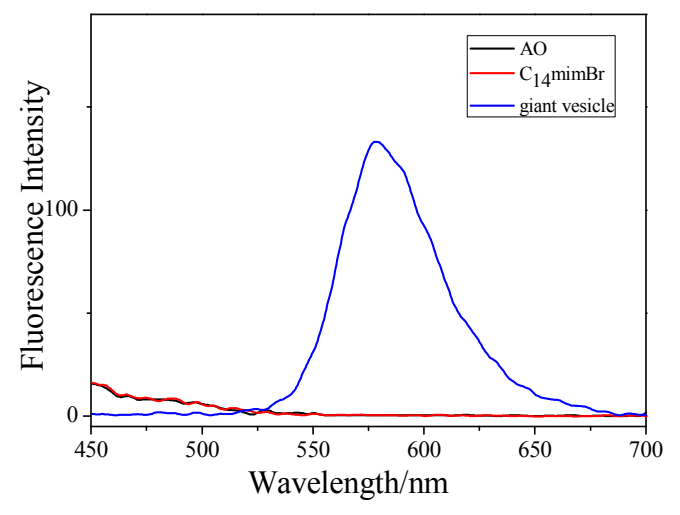

Figure S5. Fluorescence spectra of $0.5 \mathrm{mmol} \mathrm{L}^{-1} \mathrm{AO}, 0.5 \mathrm{mmol} \mathrm{L}^{-1} \mathrm{C}_{14} \mathrm{mimBr}$ and giant vesicle formed by $0.5 \mathrm{mmol} \mathrm{L}-1 \mathrm{AO} / \mathrm{C}_{14} \operatorname{mimBr}\left(\left(\lambda_{\mathrm{ex}}=375 \mathrm{~nm}\right)\right.$.
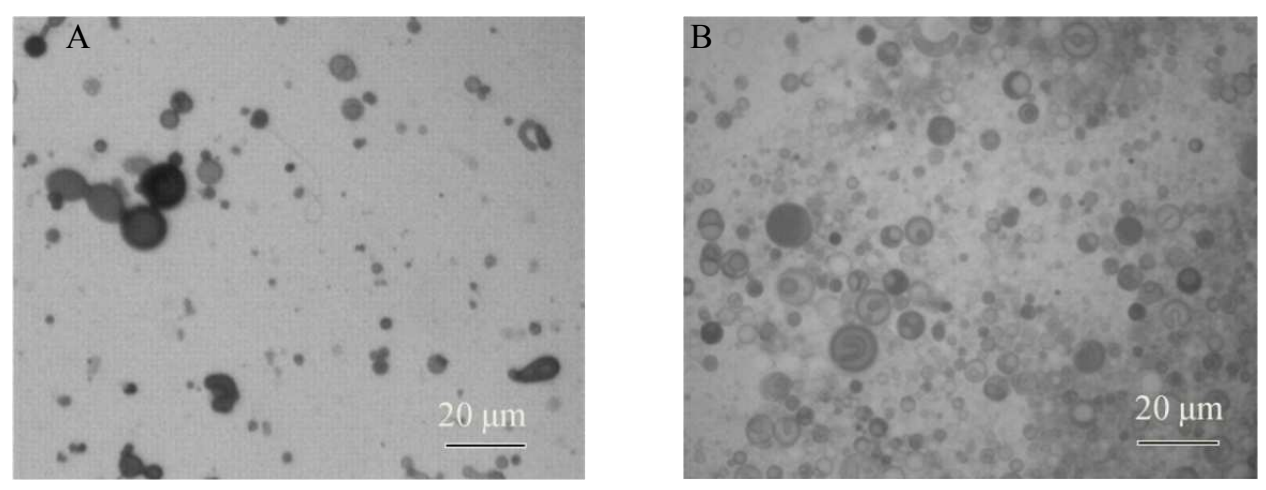

Figure S6 (A) Optical images of $2 \mathrm{mmol} \mathrm{L}^{-1} \mathrm{AO} / 2 \mathrm{mmol} \mathrm{L}^{-1} \mathrm{C}_{14} \mathrm{mimBr}$. (B) $5 \mathrm{mmol} \mathrm{L} \mathrm{m}^{-1} \mathrm{AO} / 5 \mathrm{mmol}$ $\mathrm{L}^{-1} \mathrm{C}_{14} \operatorname{mimBr}$.
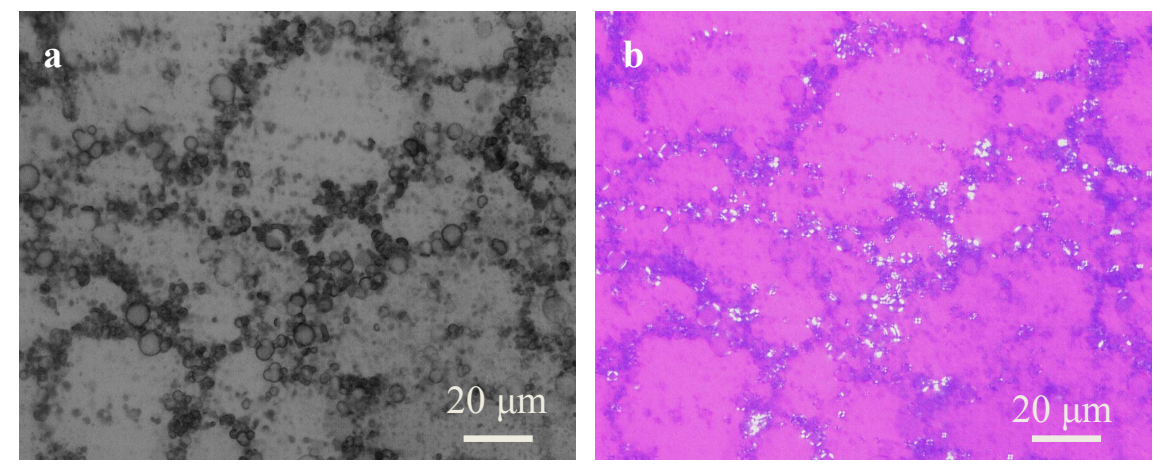

Figure S7. POM (a (without polarized light) b (with polarized light)), images of giant vesicle formed by $10 \mathrm{mmol} \mathrm{L}^{-1} \mathrm{AO} / 10 \mathrm{mmol} \mathrm{L} \mathrm{C}_{14} \mathrm{mimBr}$. 


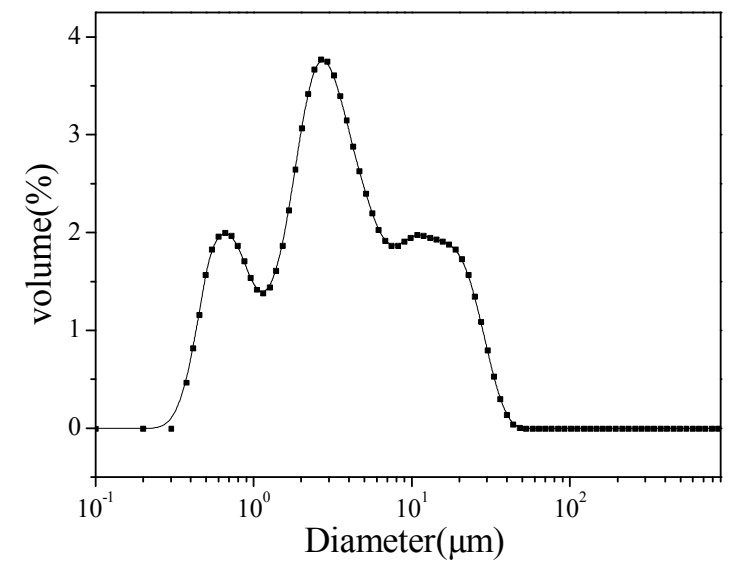

Figure S8. Size distributions of $10 \mathrm{mmol} \mathrm{L}^{-1} \mathrm{AO} / 10 \mathrm{mmol} \mathrm{L}^{-1} \mathrm{C}_{14} \mathrm{mimBr}$.
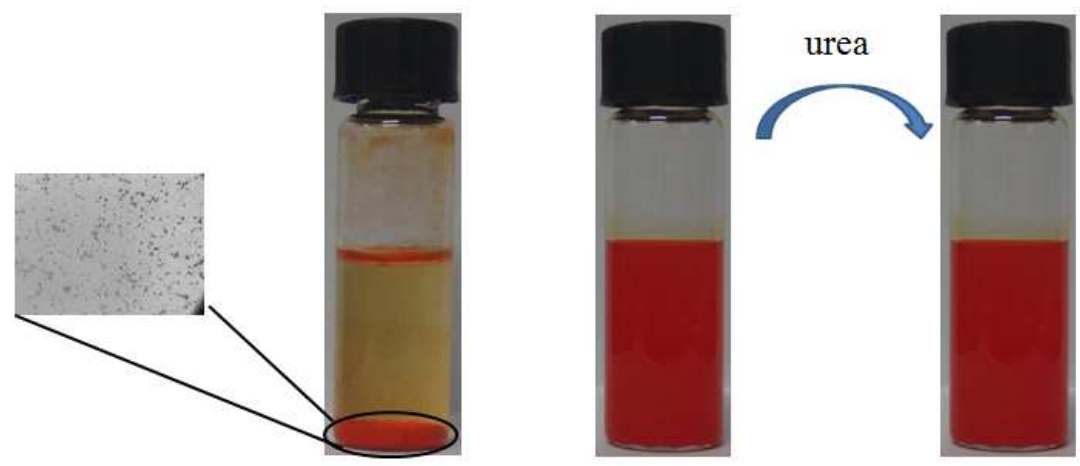

SAIL: $A O=1.2 \quad$ AO: $\quad$ SAIL $=1.2$

Figure S9. Photos of samples with different mole ratio of SAIL and AO.

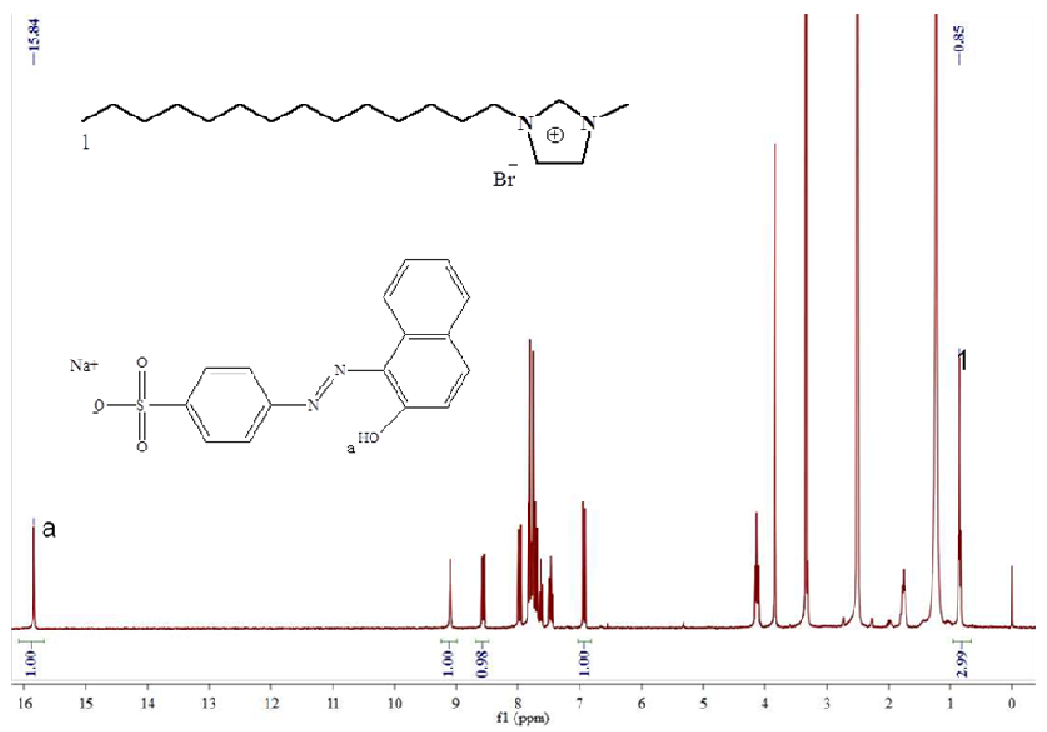

Figure S10. ${ }^{1} \mathrm{H}$ NMR spectra of precipitate of $0.5 \mathrm{mmol} \mathrm{L}^{-1} \mathrm{AO} / 0.5 \mathrm{mmol} \mathrm{L}{ }^{-1} \mathrm{C}_{14} \mathrm{mimBr}$. 


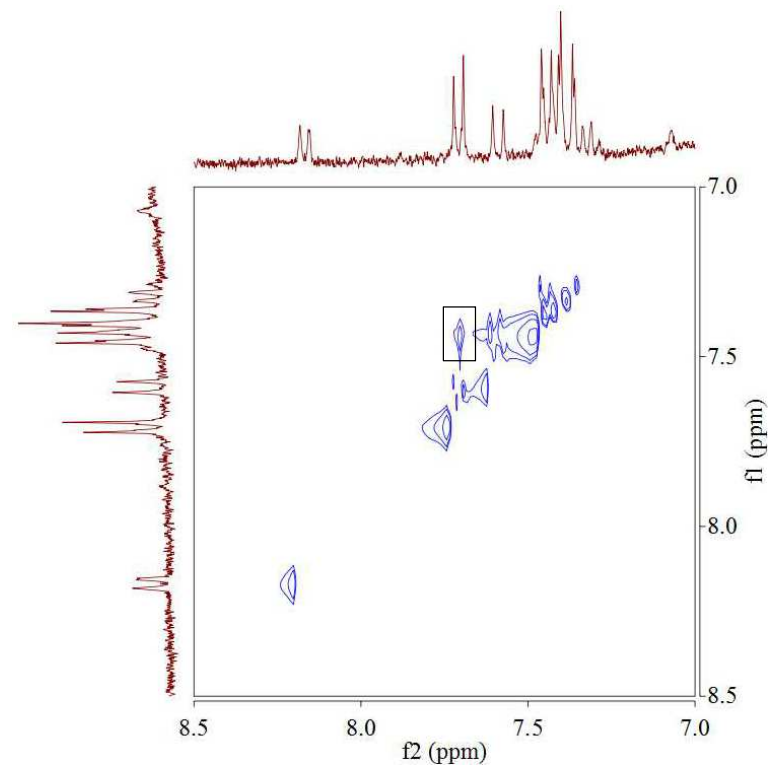

Figure S11. 2D NOESY spectra of $\mathrm{AO} / \mathrm{C}_{8} \operatorname{mimBr}\left(\mathrm{D}_{2} \mathrm{O}\right)$.

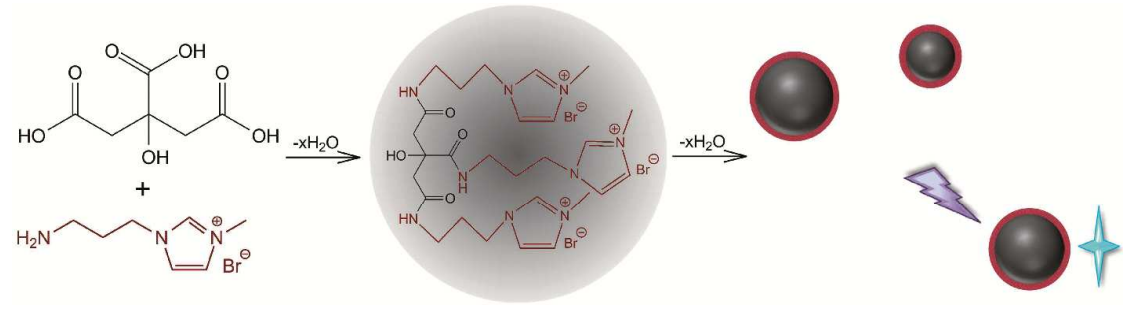

Figure S12. Schematic illustration of formation procedures of CQDs. 


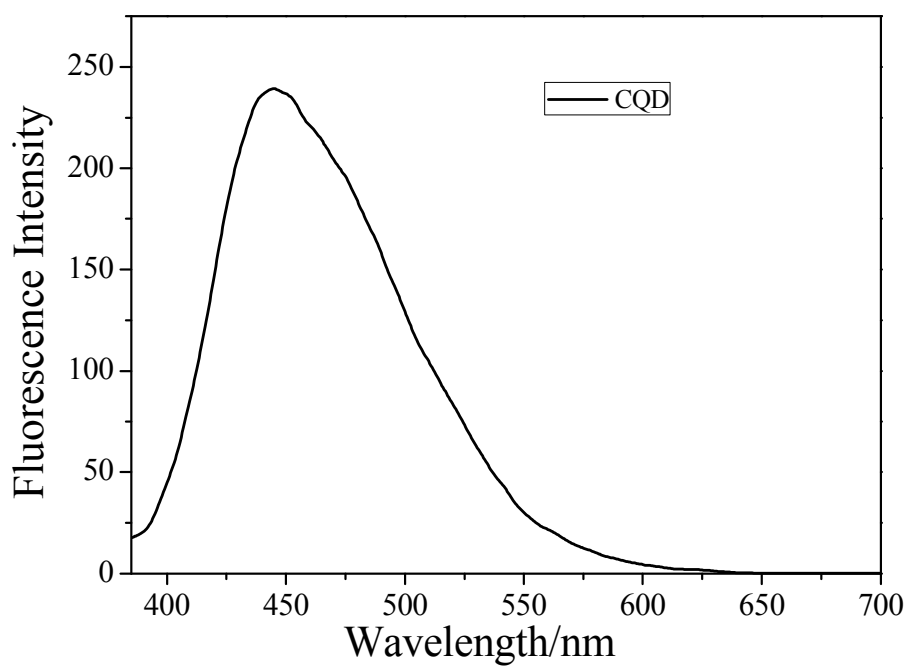

Figure. S13. Fluorescence spectra of CQD $\left(\lambda_{\mathrm{ex}}=365 \mathrm{~nm}, c=0.003 \mathrm{mg} \mathrm{mL}^{-1}\right)$.

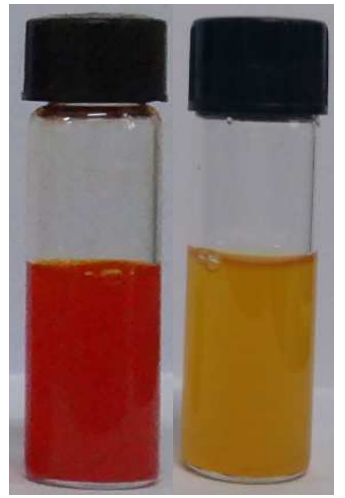

Figure S14. Photos of sample of $10 \mathrm{mM} \mathrm{AO} / 10 \mathrm{mM} \mathrm{C}_{14} \mathrm{mimBr}$ before (left) and after (right) the addition of $\mathrm{NaBH}_{4}$ 


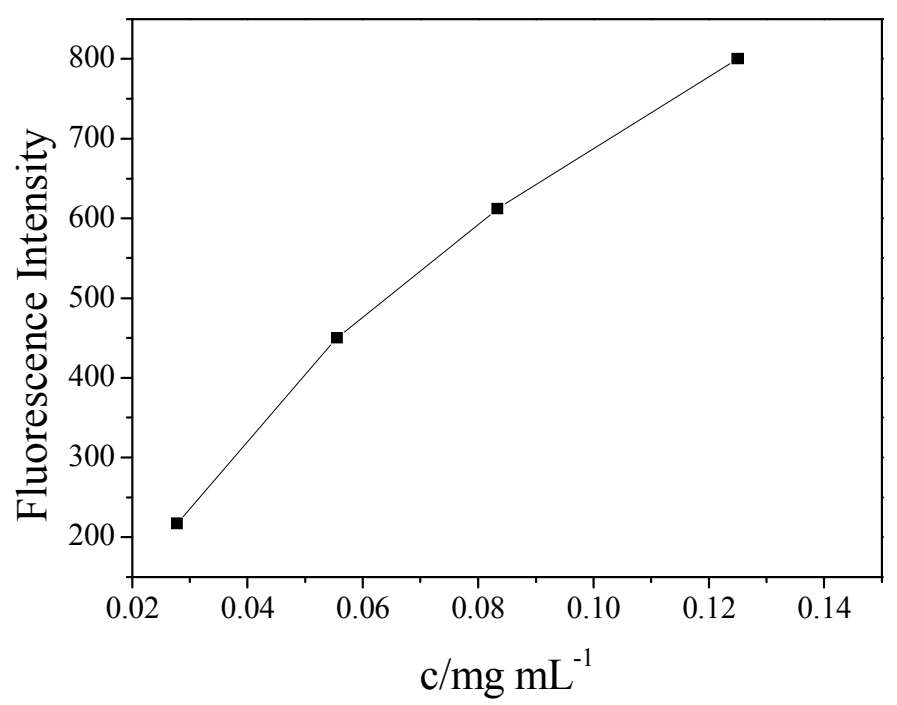

Figure S15. Standard curve of fluorescence intensity of CQD at $\mathrm{n}=445 \mathrm{~nm}$.

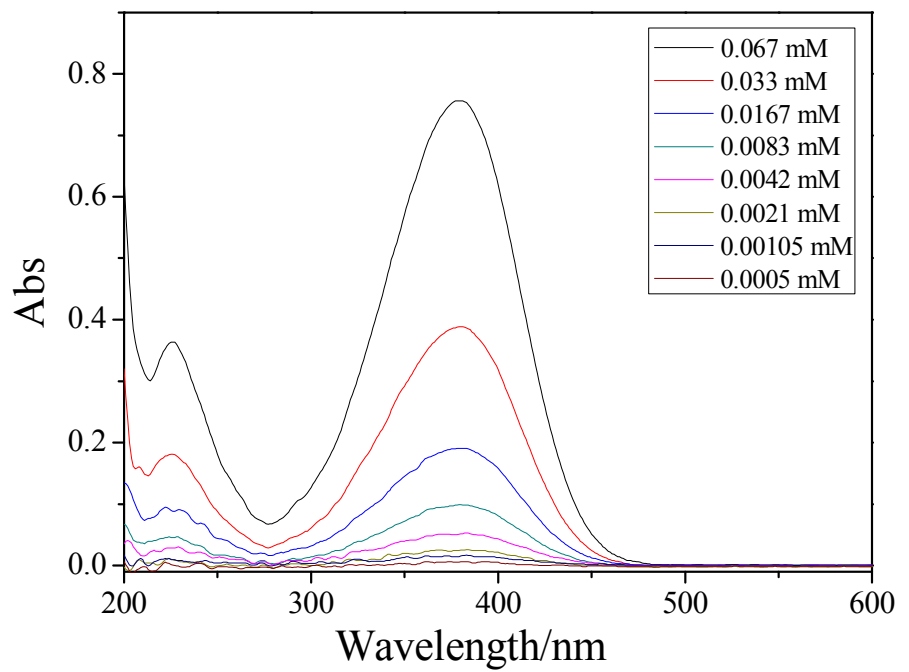




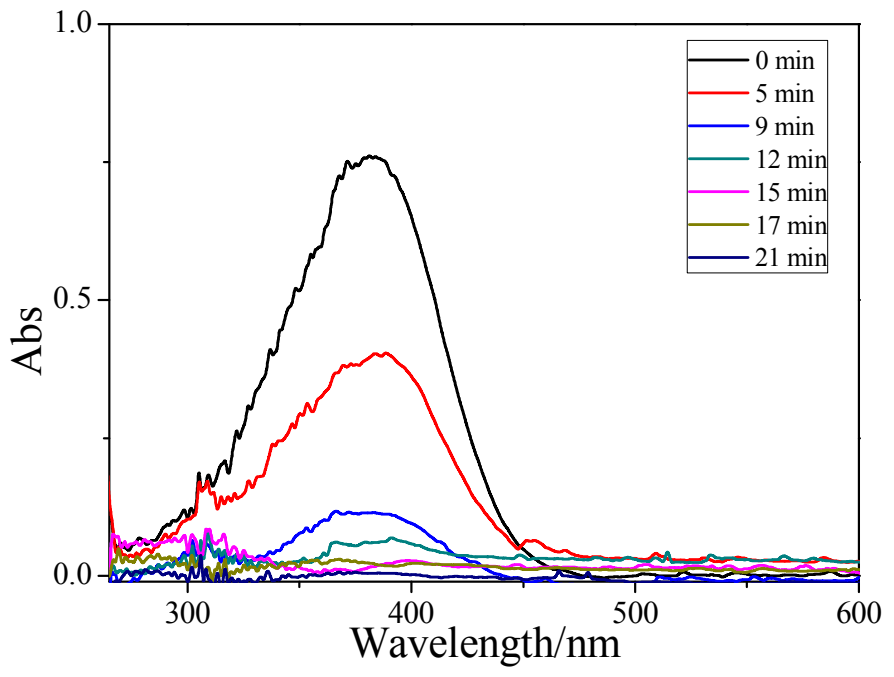

Figure S16. Time dependent UV-Vis curve of 4-nitroaniline solution with the addition of Ag nanoparticles (first cycle).

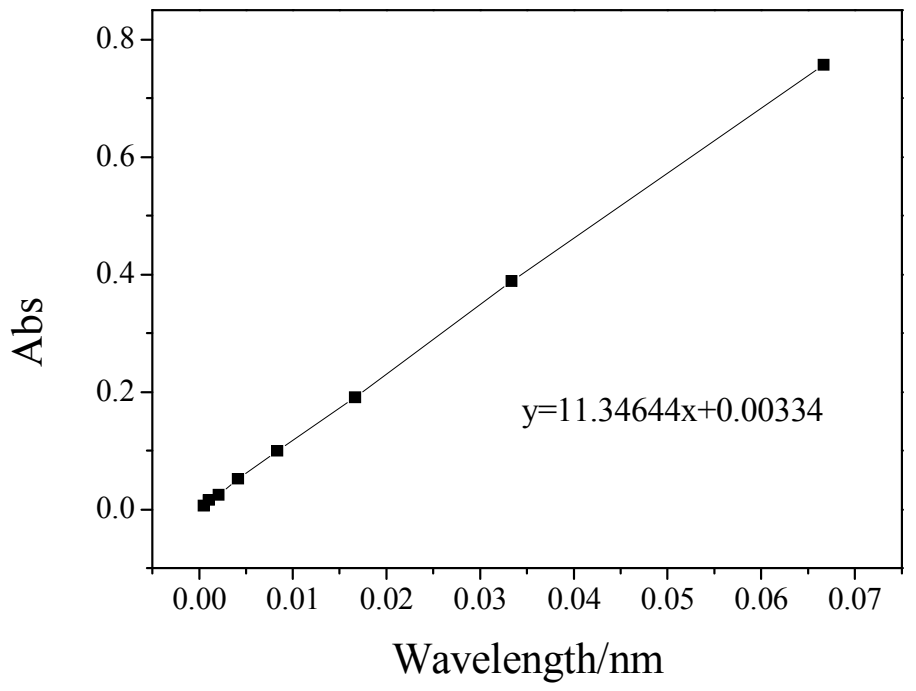

Figure S17. UV-Vis standard curve of 4-nitroaniline. 


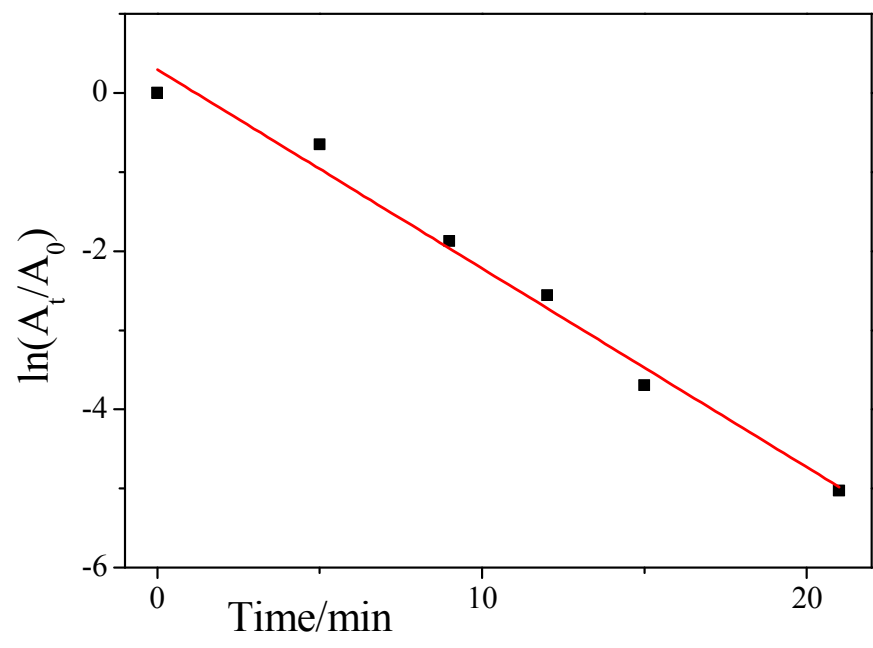

Figure S18. The corresponding linear relationship between $\ln \left(\mathrm{A}_{\mathrm{t}} / \mathrm{A}_{0}\right)$ and reduction time. 